\title{
A Pragmatic Research on College Students' English Communication Competence Cultivation
}

\author{
Jian-Min CHEN \\ Shandong University of Political Science and Law, China \\ Email: jianminchen@126.com
}

Keywords: interactive approach, communicative competence, two-sided test.

\begin{abstract}
The final goal of English teaching is to enable learners to communicate in English, that is, to cultivate students' communicative competence. However, the current state of College English teaching is far from this goal. Based on experiments, questionnaires and data analysis, this research is going to explore the reasons and analyze specific influences of the interactive approach on students' communication competition cultivation.
\end{abstract}

\section{Introduction}

The past few years have seen a positive transition in college English teaching (CET) in China from the traditional approaches to the modern ones. In the traditional way, theorists and practitioners complain much emphasis is placed on the transmission of linguistic knowledge with a neglect of the development of the students' communicative competence. Especially in China today, in the year 2016 we have taken great pace in college English reforms from liberal education professional English teaching based on new College English Teaching Syllabus. College students' English communication competence has become a very typical topic to be studied in the future.

From both the linguistic and pedagogic points of view, the focal point in College English teaching lies in how to construct a meaningful or authentic language environment for students to practise the target language, how to arouse the students' motivation, interest and initiatives to learn the language, and how to encourage their participation in classroom activities, which will then enhance the students' learning strategies and learner autonomy with the help of their own experience. In fact, the related researches have been focused on what action the teacher takes and what response the students give during the teaching process in terms of the contribution of the classroom teaching to language development, hence classroom interaction has become the centrality. In other words, CET classroom is an important setting for language learning, and the teaching process is that of communication during which the teacher and students exchange their ideas and express their meanings. As Straub (1997) puts it, "Communication, whether in speech or writing, remains our central goal as language teacher. Communication derives essentially from interaction." As far as the reform of CET is concerned, whether it can be regarded as successful or not depends on how and to what degree the classroom teaching can be made interactive with the explicit target on developing the students' communicative competence or comprehensive competence for actual use.

\section{Students' Low Communicative Competence at present}

As we know, English learning is a process which is involved in various factors such as teachers, students, language environment, and language policy. Students' low communicative competence is contradictory to the goal of College English teaching and frustrates current teaching and learning. What's more, classroom is regarded as a place where students attain knowledge and skills and classroom teaching is a main teaching mode in our present education system. So I made this investigation just to find the causes which happen in classroom. 
Table 1 Students' Data

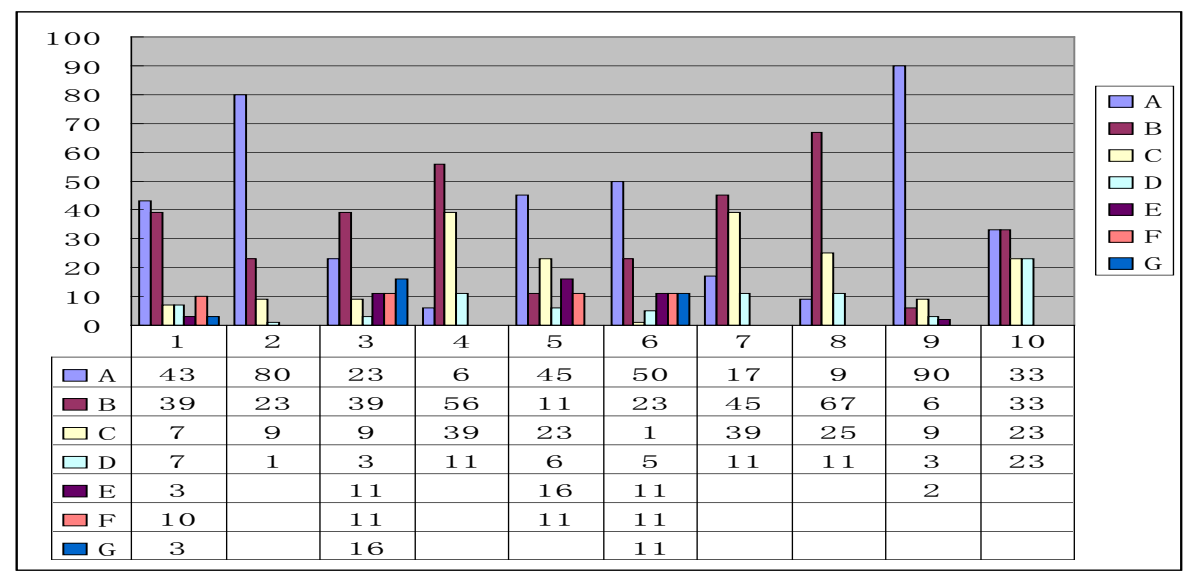

I gave ten questions about students' self-assessment, teacher's teaching methods, teacher's, teaching materials, classroom management and resources, and teacher's functions to help students learn English. From the results of table1, we can find:

1) Students hope to improve their English proficiency (Q5, Q6, Q7 ). They long to get as much knowledge as possible in classroom. They are bored at the passive role as a receiver, which requires teachers to adopt more scientific and various measures into classroom. Obviously only reference books cannot meet their needs.

2) $67 \%$ of the students hope that the classroom style is a flexible combination of games, students' discussion and teacher explanation (Q8). They are eager to be involved in class activities and display their initiative. But they benefit little from others students' speaking. This requires teachers managing classroom skillfully.

3) However, to some extent, the present examination system (CETB and 4and Band 6) has restricted students' eagerness to develop their communicative competence, which results in students' dissatisfaction with the present College English teaching (Q4, Q6 ).

4) In daily learning, students mainly depend on some written materials including newspapers, magazines and reference books to improve their English and Internet resources are seldom made use of (Q10).

Table 2 Teachers' Data

\begin{tabular}{|c|c|c|c|c|c|c|c|c|c|c|c|c|c|c|}
\hline \multirow[t]{2}{*}{ N0. } & \multicolumn{2}{|l|}{ A } & \multicolumn{2}{|l|}{ B } & \multicolumn{2}{|l|}{ C } & \multicolumn{2}{|l|}{ D } & \multicolumn{2}{|l|}{$\mathrm{E}$} & \multicolumn{2}{|l|}{$\mathrm{F}$} & \multicolumn{2}{|l|}{ G } \\
\hline & $\mathrm{Am}$ & Per\% & $\mathrm{Am}$ & Per & $\mathrm{Am}$ & Per & $\mathrm{Am}$ & Per & $\mathrm{Am}$ & Per & $\mathrm{Am}$ & Per & $\mathrm{Am}$ & Per \\
\hline 1 & 10 & $50 \%$ & 2 & $10 \%$ & 1 & $5 \%$ & 3 & $15 \%$ & 2 & $10 \%$ & 1 & $5 \%$ & 1 & $5 \%$ \\
\hline 2 & 13 & $65 \%$ & 3 & $15 \%$ & 3 & $15 \%$ & 1 & $5 \%$ & & & & & & \\
\hline 3 & 10 & $50 \%$ & 1 & $5 \%$ & 4 & $20 \%$ & 5 & $25 \%$ & 0 & $0 \%$ & & & & \\
\hline 4 & 6 & $30 \%$ & 2 & $10 \%$ & 4 & $20 \%$ & 8 & $40 \%$ & & & & & & \\
\hline 5 & 3 & $15 \%$ & 2 & $10 \%$ & 4 & $20 \%$ & 11 & $55 \%$ & & & & & & \\
\hline 6 & 3 & $15 \%$ & 8 & $40 \%$ & 1 & $5 \%$ & 2 & $10 \%$ & 5 & $25 \%$ & 1 & $5 \%$ & & \\
\hline 7 & 6 & $30 \%$ & 8 & $40 \%$ & 5 & $25 \%$ & 1 & $5 \%$ & 0 & $0 \%$ & & & & \\
\hline 8 & 0 & $0 \%$ & 2 & $10 \%$ & 4 & $20 \%$ & 12 & $60 \%$ & 2 & $10 \%$ & & & & \\
\hline 9 & 6 & $30 \%$ & 8 & $40 \%$ & 2 & $10 \%$ & 2 & $10 \%$ & 2 & $10 \%$ & 0 & $0 \%$ & & \\
\hline 10 & 5 & $75 \%$ & 4 & $20 \%$ & 1 & $5 \%$ & 0 & $0 \%$ & & & & & & \\
\hline
\end{tabular}

No. $=$ Question Number Am $=$ Amount $\quad$ Per $=$ Percentage

I also gave ten questions about teacher's teaching style, methods and opinions about English 
teaching to 20 teachers. From the results, we can find that

1) The traditional teaching methods are still prevalent in the classroom teaching: $50 \%$ teachers still pay most attention to grammar, words and phrases (Ql), 65\% teachers still dominate the classroom which is still teacher-centered(Q2).

2) The reasons that lead to this phenomenon lie in: historical reasons (Q3) and practical reasons $(Q 7, Q 8)$--- for quite a long time, grammar-translation method has been a dominant method in language teaching in our country, and this method has had a profound influence on most teachers. Besides, the population of China is large and teaching resources, especial teacher resources, are comparatively limited. There are too many students in one class, which prevents teacher from adopting those methods which are helpful to improve students' communicative competence to accomplish our teaching task.

3) Although most teachers have established consciousnesses of student-centeredness and cultivating students' ability of real using English (Q4,Q5,Q9), it is very difficult for teachers to apply these ideas into their English teaching and there is still great difference and distance between theory and practice.

4) The investigation also indicated that teachers mainly depend on reference books to prepare their lessons the limited knowledge of which cannot obviously meet students' need for more learning resources. It is necessary for teachers to use more modern teaching instruments to provide students with more learning resources (Q10). To learn software and Internet is a good tool for students' English learning.

\section{Interactive Approach and Students' Communicative Competence}

In order to testify whether the interactive approach has great influence on students' communicative competence, I gave the questionnaires to 193 (112 males, 81 females) freshmen of second semester from five classes taught by the interactive approach including two classes of teacher A of questionnaire I .

\section{Three aspects of the Interactive Approach on Students' Communicative Competence}

Table 3 Teacher talk and students’ communicative competence

\begin{tabular}{|c|c|c|c|}
\hline Item No. & Mean & Std. D & SE.M \\
\hline 1 & 3.01 & .542 & .035 \\
\hline 2 & 4.76 & .712 & .048 \\
\hline 3 & 4.60 & .591 & .071 \\
\hline 4 & 4.69 & .570 & .054 \\
\hline 5 & 4.59 & .514 & .058 \\
\hline 6 & 4.72 & .572 & .060 \\
\hline 7 & 4.85 & .624 & .075 \\
\hline 8 & 4.90 & .543 & .063 \\
\hline 9 & 4.71 & .587 & .069 \\
\hline 10 & 4.57 & .672 & .049 \\
\hline 11 & 4.65 & .575 & .051 \\
\hline
\end{tabular}

From the descriptive test, we have known that teacher talk has the strongest impact on students' communicative competence. As the information of Table 4.9 shows, all the item scores except Item 1 are between four and five, which means the participants' responses to these statements are 
“always agree”.

First, the mean value (mean=4.90) of Item 8 (style of teacher talk) is the highest among those of all the items. Besides, the mean values of Item 9 (proportion of teacher talk) and Item 11 (referential questions of teacher talk) are 4.71 and 4.65, which are notable too. 90\% (Table 4.10 Question2) of the participants completely agreed that their communicative competence can be stimulated by encouraging and meaningful teacher talk. Moreover, 88\% (Table 4.11 Question1) of the participants completely agreed that proper proportion of teacher talk in class has an influence on students' communicative motivation. It shows that in most students' eyes, Teacher talk in class is the most important and influential to their communicative competence.

Second, from the information of the table above, we can see students pay much attention to the oral English level of teacher talk, because means of Item 6 (mean=4.72) and Item 7 (mean=4.85) are high too. The mean value of Item 7 (fluency of teacher talk) is just slightly lower than that of Item 8 (mean=4.90). 74\% (Table 4.12 Question7) of the subjects completely agreed that fluent teacher talk has an impact on their communicative competence. From students' responses to the questionnaires, it is concluded that the oral English level of teacher talk can influence students' communicative competence.

Third, the scores of Item 2 (mean=4.76), Item 3 (mean=4.60) and Item 4 (mean=4.69) are noticeable, concerning the content of teacher talk, which means good topics of teacher talk will make students more interested in what they are learning, namely to stimulate their communicative motivation.

Moreover, attentions should be paid to Item 1 (mean=3.01), which is related to the explanatory teacher talk. Though the value of the item is at the mediate level, we should also pay close attention to our explanatory language in class.

Table 4 Student talk and students’ communicative competence

\begin{tabular}{|c|c|c|c|}
\hline Item No. & Mean & Std. D & SE.M \\
\hline 12 & 3.45 & .541 & .070 \\
\hline 13 & 4.10 & .612 & .076 \\
\hline 14 & 3.68 & .509 & .027 \\
\hline 15 & 4.61 & .524 & .068 \\
\hline 16 & 4.57 & .638 & .061 \\
\hline 17 & 4.52 & .662 & .053 \\
\hline 18 & 4.02 & .518 & .047 \\
\hline 19 & 4.23 & .582 & .046 \\
\hline 20 & 3.78 & .712 & .051 \\
\hline 21 & 3.57 & .570 & .054 \\
\hline 22 & 4.45 & .721 & .057 \\
\hline
\end{tabular}

As we can see in Table 4, the mean item value of Part II is only slightly lower than that of Part I, which means student talk is also important to students' communicative competence. The following table tells us the results of descriptive statistics of the influence of student talk. All the item scores are larger than three and the mean values of $63.6 \%$ of the items are between four and five.

In Table 4, the most remarkable figures are 4.61, 4.57 and 4.52 in Items 15, 16 and 17 respectively and 70\% (Table 4.14 Question20) of the participants completely agreed that appropriate forms of student talk are helpful to communicative competence. The results make it clear that English group discussion, class debate and individual speech are very important and can help to cultivate students' communicative competence. Besides, the mean values of Item 19 
(mean=4.23) and Item 22 (mean=4.45) are worth whistle. Item 19 is related to content of student talk and Item 22 refers to percentage of student talk in class.

Attentions also should be paid to Item 13 (patterns of student talk) and Item 18 (topics of student talk), because both of the mean values exceed four. The mean value of Item 13 is 4.10, suggesting that good patterns of student talk help to enhance the communicative competence of the students, and that of Item 18 is 4.02, indicating that students' communicative competence may be improved if they have suitable topics to communicate with.

Table 5 Teacher’s feedback and students' communicative competence

\begin{tabular}{|c|c|c|c|}
\hline Item No. & Mean & Std. D & SE.M \\
\hline 23 & 4.35 & .677 & .053 \\
\hline 24 & 4.38 & .586 & .054 \\
\hline 25 & 3.96 & .621 & .048 \\
\hline 26 & 2.76 & .723 & .061 \\
\hline 27 & 3.04 & .645 & .046 \\
\hline 28 & 3.01 & .512 & .048 \\
\hline 29 & 2.65 & .697 & .074 \\
\hline 30 & 2.34 & .583 & .078 \\
\hline
\end{tabular}

As displayed in Table 5, the mean value of the responses to teacher's feedback is 3.31 on a five-point scale, which means the influence of teacher's feedback on students' communicative competence is mediocre.

But from the information of Table 5, we can see that the mean values of Item 23 (initiative feedbacks, mean=4.35) and Item 24 (positive feedbacks, mean=4.38) are higher than those of other items of Part III, which means teacher's feedbacks that could initiate new response from the same student or another student may be helpful to enhance students' communicative competence, with positive feedbacks encouraging them.

In addition, the mean values of Item 27 (negative feedbacks) and Item 28 (no feedbacks) are over three. It shows, to a certain extent, teacher's immediate feedbacks, especially positive ones are important for cultivating students' communicative competence. Besides, the mean values of Items 26, 29 and 30 are 2.76, 2.65 and 2.34 respectively. It means that feedbacks are necessary but the styles of them won't impose much effect on students' communicative competence.

Table6 Analysis of the Three aspects

\begin{tabular}{|c|c|c|c|}
\hline & $\begin{array}{c}\text { Teacher talk } \\
(\text { Part I) }\end{array}$ & $\begin{array}{c}\text { Student talk } \\
(\text { Part II) }\end{array}$ & Teacher's feedbacks (Part III) \\
\hline Mean & 4.551 & 4.092 & 3.310 \\
\hline Std. D & .558 & .784 & .592 \\
\hline F & \multicolumn{3}{|c|}{26.038} \\
\hline Sig. & \multicolumn{3}{|c|}{.000} \\
\hline Comments & \multicolumn{3}{|c|}{ Part I>Part II>Part III } \\
\hline
\end{tabular}

*The mean difference is significant at the .05 level.

In order to further explore the relationship between different aspects of the interactive approach and to specify which aspect of it has the strongest influence on students' communicative competence. One-Way ANOVA analysis was carried out. Three sets of mean values of the three parts of the questionnaire were calculated respectively and a comparison was made between them to see whether there were statistically significant differences. 
As shown in Table6, the results of ANOVA test indicates significant between-group differences exist among participants' responses to the three aspects of the interactive approach $(F=26.038$, $p=.000$ ). Moreover, the mean value of Part I exceeds that of Part II as well as that of Part III, so teacher talk is the most important factor for cultivating students' communicative competence. Then the mean value of Part II is larger than that of Part III, which means in the interactive class student talk should also be followed with interest to improve students' communicative competence and although teacher's feedbacks are of enough importance for our teaching aim, it is still the least influential aspect on students' communicative competence.

\section{Conclusion}

Table 7 The interactive approach and students' communicative competence

\begin{tabular}{|c|c|c|c|}
\hline Number of Cases & Mean & Std. D & Variance \\
\hline 193 & 3.984 & .554 & .138 \\
\hline
\end{tabular}

As in Table 7 , of all the 30 items, means within the middle range $(2.5 \leq$ mean $\leq 3.5)$ count six, while 23 items are in the high range $(3.5<$ mean $\leq 5)$. Only one items falls in the low range $($ mean $<2.5)$. The three items which the students agreed most are respectively Item 8 (mean=4.90), Item 7 (mean=4.85) and Item 2 (mean=4.76). All of them belong to Part I, which refers to teacher talk. The three items which the students agreed least are Item 30 (mean=2.34), Item 29 (mean=2.65) and Item 26 (mean=2.76). They all fall within Part III, teachers' feedback.

On the whole, the statistical analysis shows that the mean value of the 30 items is 3.984, which is over three, indicating that the interactive approach has great influence on students' communicative competence.

\section{References}

[1]Campbell, C. (2004). Teaching second language writing: interacting with text.Beijing: Foreign Language Teaching and Research Press.

[2]Dörnyei, Z. \& Ottò, I. (1998). Motivation in action: A process model of L2motivation. Applied Linguistics, 4, 43-49.

[3]Johnson, K. (2002). An introduction to foreign language learning and teaching.Beijing: Foreign Language Teaching and Research Press.

[4]Nunan, D. (2001). The learner-centered curriculum: a study in second language teaching. Cambridge: Cambridge University Press.

[5]Straub, R. (1997). Students' reactions to teacher comments: an exploratory study. Research in the teaching of English, 31, 91-143. 